\title{
THE USAGE OF INTERACTIVE TRAINING METHODS IN THE DEVELOPMENT OF FUTURE LAWYER'S PROFESSIONAL SELF- CONSCIOUSNESS
}

\author{
Mikhail Demidov $^{1}$, Mikhail Smirnov ${ }^{2 \star}$, Polina Starygina ${ }^{3}$, Olga Yakhina ${ }^{4}$ \\ ${ }^{1}$ Russian University of Cooperation, Cheboksary, Russian Federation, mvdemidov@yandex.ru \\ ${ }^{2}$ Mari State University, Yoshkar-Ola, Russian Federation, micsha.smi2015@yandex.ru \\ ${ }^{3}$ Mari State University, Yoshkar-Ola, Russian Federation,poly222@yandex.ru \\ ${ }^{4}$ Mari State University, Yoshkar-Ola, Russian Federation, olgeens@mail.ru \\ ${ }^{*}$ Corresponding Author
}

\begin{abstract}
The most important problem of education is developing professional self-consciousness of future legal specialists. It is determined by the necessity of rapid adaptation to modern dynamic life and conditions of practical activity. The vast array of current legislation, its frequent changes, gaps and conflicts require lawyers to have a high level of theoretical knowledge and law enforcement practice.

Questions of the lawyer's professional self-consciousness development becomes particularly relevant because of contradictions between the existing level of practical training of future specialists and the objective needs of improving higher legal education. In this regard an important socio-psychological task of higher education is the formation of professional self- consciousness of a specialist as an essential prerequisite for further successful activities. In addition the problem of creating such conditions that would promote development the lawyer's self-consciousness is very important. As practice shows specialists who are able to integrate changes in surrounding world into the context of the cognitive, emotional and behavioral components of their personality can adjust themselves to the changes of professional activity. Success of this adaptation is determined by the qualitative characteristics of the professional self-consciousness of a young specialist.
\end{abstract}

Keywords: professional self-consciousness, interactive teaching methods, professional activity

\section{INTRODUCTION}

Questions of the lawyer's professional self-consciousness development become particularly relevant because of contradictions between the existing level of practical training of future specialists and the objective needs of improving higher legal education. In this regard an important socio-psychological task of higher education is the formation of professional self-consciousness of a specialist as an essential 
prerequisite for further successful activities. In addition the problem of creating such conditions that would promote development the lawyer's self-consciousness is very important. As practice shows specialists who are able to integrate changes in surrounding world into the context of the cognitive, emotional and behavioral components of their personality can adjust themselves to the changes of professional activity. Success of this adaptation is determined by the qualitative characteristics of the professional self- consciousness of a young specialist.

\section{PURPOSE}

The problem of purposeful development of professional self-consciousness of future lawyers in the conditions of higher education remains poorly developed in psychology.

\section{Such problem includes:}

- Lack of a unified approach to the development of the psychological structure of the lawyer's professional self-consciousness;

- Lack of a scientifically-based system for the formation of professional self- consciousness of the future lawyer in the conditions of university training.

Therefore it is very important and relevant to determine the structural and content components and scientific justification of the professional self- consciousness dynamics in legal education, using interactive teaching methods.

The process of developing the professional self- consciousness of a law student will be more effective if their professional training of students is based on the introduction of interactive forms and methods of teaching. Methods should be based on learning through action, reproducing situations, relationships, typical tasks of the daily work of a lawyer. These are specially developed systems of special courses and seminars, video presentations, business games, psychological trainings, etc. In the course of this activity the necessary knowledge is acquired and professional self-consciousness is developed generally, including its main structural components: intellectual, communicative, affective-volitional and motivational.

\section{METHODS AND MATERIALS}

The following set of methods was used as a methodological tool for diagnosing the level of professional selfconsciousness development. Set of methods included theoretical and system-structural analysis of scientific literature on the problem:

1) Expert evaluation;

2) Oral and written surveys in free and standardized forms, content analysis of activity products, methods of psychodiagnostic testing of emotional, volitional, motivational, cognitive characteristics, questionnaires to identify the orientation and self-esteem of the individual;

3) As methods of diagnosis of changes in the level of development of professional identity, were used: Cattell's 16 personality factors test, Bass Orientation Inventory, V.E. Milman's methods, the test of "Individual Thinking Patterns" A. Alekseev and L. Gromova, the method of determining the dynamics of the severity of self-control G. S. Nikiforov, V. K. Vasilyev and S. V. Firsova and test "Leading Representative System" L. Stolyarenko;

4) Written survey of students (questionnaire);

5) Method of statistical processing of data with using a package of computer mathematical statistics: STATISTICA, STAT-TOR (comparative analysis by the Student's t-test, factor analysis with the calculation of the factor matrix and factor diagram).

\section{RESULTS AND DISCUSSION}

The study of individual consciousness implies it's as a multi-level system that includes both conscious and unconscious components. Methods of experimental psychosemantics of consciousness were developed in the early 80 's. It leads to the advanced the solution of the problem in the aspect of the relationship between consciousness and the sub consciousness.

According to many authors professional self- consciousness is a part of the general self-consciousness of the individual. Such consciousness is treated as a psychological formation, which plays an important role in the regulation of activity of the individual based on professional knowledge, self-knowledge as a subject of professional activity, as well as emotional-value attitude to yourself as a professional. 
Thus E. Yu. Artemieva states that the world of the profession is an integral part of the subjective model of the world image for professionals. This world has its own "quasi-measurement", "semantic field", systems of meaning and significance "understood as traces of activity recorded in relation to their objects". This means that the professional perceives the surrounding reality and himself in connection with the experience of activities [1].

V. N. Koziev considered professional self-consciousness as a complex personal mechanism that plays an important role in regulating activities. It helps to assess existing professional qualities, achievements, planning directions for self-development, and forming professionally significant qualities of a professional's personality [2].

According to R. V. Gabdreev, A. A. Derkach, V. N. Koziev, E. A. Klimov, N. V. Kuzmina, V. D. Shadrikov professional self-consciousness is an integrative formation that affects the professional development of the individual, abilities, orientation, character and affects the effectiveness of professional activity. These scientists note that the structural nature of professional self-consciousness includes the following personality features: intellectual (thinking), moral (behavior), emotional (feelings), volitional (ability to self-manage), organizational (mechanism of activity) [2,3,4,5,6,7].

Theoretical analysis of the literature leads to the conclusion that professional self-consciousness is the main factor that integrates professionally significant personality qualities and their expression in activities and behavior. It is a complex, hierarchical structure that combines ideas about personality, content and conditions of activity, models of professional behavior.

The professional activity of a lawyer is complex and diverse. It combines a wide variety of challenges and legal regulation of all actions performed with high emotional tension, the organization of own work and communication activities. In condition of socio-economic instability legal activity is significantly more complex. It affects the internal, psychological resources of the individual, which determine the understanding of changes, attitude to them, assessment of the ability to influence them and awareness of the need to adapt activities and behavior adequately to these changes.

According to scientific publications the conditions for effective regulation of purposeful formation of lawyer's professional self-consciousness have not been fully studied yet. The problem of developing professionally important qualities of a future lawyer has not received a clear theoretical explanation and has not provided access to practice yet. Modern conditions can be characterized by the instability of the socio-economic surroundings. As usual training and selection of lawyers is based on the assessment of a number of psychological qualities, as well as professional competence, including theoretical and practical training. However, these indicators are not an accurate basis for predicting and achieving a high level of professional activity productivity. This problem can be solved by appeal to psychological mechanisms of the individual integration, the most important of which are consciousness and self-consciousness, including professional self-consciousness.

As practice and analysis of scientific works shows currently most universities use the information model of training. The existing model of future specialist training is quite simple: taking knowledge - memorizing and processing - demonstrating the degree of assimilation of the received information.

It is well known that comprehensive development of a professional's personality can not be achieved if the educational process is planned only on the basis of the need to transfer and perceive knowledge. Education is inefficient when professional training is presented only as a set of educational concepts and is provided only with notes of lectures and seminars, and is controlled exclusively by examination of knowledge.

According to available researches in the field of higher education pedagogy and psychology the information model of training is not able to develop many professionally important qualities, including the professional self-consciousness of future lawyers to the required level. In our opinion the main reason for this negative phenomenon is ineffective system (methods and technologies) for training future specialists.

Interactive methods imply joint learning (learning in collaboration) in which both students and the teacher are the subjects of learning. The teacher acts as a more experienced organizer of the learning process. All participants interact with each other, exchange information, solve problems together, model situations and evaluate the actions of colleagues and their own behavior in the educational process. Students are immersed in a real atmosphere of business cooperation in solving problems, optimal for developing the skills and qualities of a future lawyer.

At the Law Faculty of Mari State University the use of interactive methods is based on learning through action, when typical daily situations, relationships, tasks and problems of the lawyer's work are reproduced. 
The main forms of interactive learning classes are problem seminars, round tables, creative (problem) tasks, Socratic dialogue, brainstorming, role-playing games (modeling of trials and other procedural actions), video presentations and others.

\section{CONCLUSION}

We can talk about professional self-consciousness as a special phenomenon of the human psyche basing on the theoretical basis of well-known Russian and foreign researchers. Self-consciousness determines the self-regulation of a person's actions in the professional sphere on the basis of professional requirements knowledge, professional capabilities and emotional attitude.

A high level of professional self-consciousness development at the stage of university training is one of the conditions for the success of lawyer's professional duties in real working life.

Professional self-consciousness of a lawyer is an integrative individual formation which components can be characterized as communicative, cognitive, affective-volitional and motivational. Lawyer's professional selfconsciousness includes following elements:

a) Independence of thinking, the ability to abstract, to search non-standard, creative ways to solve tasks which are indicators of the cognitive component;

b) Insight, diplomacy, dominance, courage in establishing social contact which are indicators of communicative component;

c) Self-control, restraint, self-confidence, the ability to self-control and lead others in psychologically stressful situations which are indicators of the affective-volitional component;

d) Interest and need in legal knowledge which are indicators of the motivational component.

The phenomenon of professional self-consciousness which is often the object of close attention of representatives of psychological science is not fully studied today. The task of modern researchers in the scientific fields of labor psychology and pedagogical psychology is to understand how self - consciousness can be formed and developed; to determine which mechanisms fill with competence components.

Learning technologies that are based on the cooperation of students and teachers when both become subjects of learning are optimal for the development of professional self- consciousness. All participants interact with each other, evaluate their actions; students are immersed in a real atmosphere of business cooperation in such educational process. Such learning is generally optimal for developing the professional qualities of a future lawyer.

Special courses and special practical classes (basics of clerical work, basics of speech communication of lawyers, negotiation techniques, drafting of criminal and civil procedural documents, basics of professional activity and ethics, advocacy, legal research of documents) are involved in the educational process.

Interactive learning technologies are aimed not only at development of individual cognitive processes and skills of the student, but also on the development of professional consciousness of a future specialist. They help to form sustainable cognitive and social motives, interests, aspirations to knowledge, communicative qualities. All of these features are important for successful legal work.

\section{REFERENCE LIST}

Artemieva, E. U. The Psychology of subjective semantics.- M., 1980

Koziev, V. N. Psychological analysis of professional self-consciousness. L., 1980.

Gabdreev, R. V. Space, time, movement in the professional activity of an engineer: their perception, understanding as professionally important 6 qualities / / Anthology of modern psychology of the late twentieth century / ed. Kazan, 2001. - P. 267-276. ISBN 5-89573-059-0: 500 copies.

Derkach, A. A., Orban, L. E. Acmeological foundations of professional maturity formation- Moscow: rags, 1995. -208 p.

Kuzmina, N. V. Acmeology - on the factors of reaching the top in professional activity/ Problems of improving 
Proceedings of SOCIOINT 2020- 7th International Conference on Education and Education of Social Sciences, 15-17 June 2020

professionalism and productivity of pedagogical activity. - L.: LSU, 1997. - P. 6-13.

Klimov, E. A. Developing man in the world of professions. Obninsk, 1993, 57 p.

Shadrikov, V. D. Activity and abilities. - Moscow: Logos, 1994. - 320 p. 